\title{
Isolation, Screening and Activity of Hydrocarbon-Degrading Bacteria from Harsh Soils
}

\author{
Zulfa AIDisi $^{1}$, Samir Jaoua ${ }^{1}$, Dhabia Al-Thani ${ }^{1}$, Saeed AlMeer ${ }^{2}$, Nabil Zouari ${ }^{1}$ \\ ${ }^{1}$ Department of Biological and Environmental Sciences. College of Arts and Sciences, \\ Qatar University, PoB. 2713, Doha, Qatar. \\ za1102541@student.qu.edu.qa; samirjaoua@qu.edu.qa; 199400699@student.qu.edu.qa; nabil.zouari@qu.edu.qa \\ ${ }^{2}$ Central Laboratories Unit, Qatar University, PoB. 2713, Doha, Qatar \\ salmeer@qu.edu.qa
}

\begin{abstract}
The study of microbial communities in relation to their ecology, interaction, and genetics must be covered in Qatar with special soil, weather and water. Microorganisms of an environment never having been exposed to such factors do not have necessarily the ability to resist. However, when exposed to such factors, they are often able to adapt, that is to say the potential to acquire metabolic potentialities by recruitment vertical or horizontal specific genes, or recruitment of metabolic pathways present in the genome but not expressed. In polluted environments with oil hydrocarbons, the phenomena of horizontal/vertical transfers, mutations and adaptation to environmental stressors increase the metabolic capabilities of bacteria, including expanding their range of substrates, and allow their adaptation to new substrates. Extensive research on such fields is often focusing on genetic studies, meaning that the genes pools and expression as well as species occurrence are considered as basis. However, from the biotechnological point of view, the cell is considered, as an analogy, as factory. All its components (physical structure and the functions of the organelles and metabolic activities) are strictly regulated by regulatory machineries strictly controlled by the microenvironment. This approach will help answer the question on the different microbial communities that are available in Qatar soil and how they are unique in some biological activities. Indeed, the focus of our research is to characterize and demonstrate the diversity of biological activities within bacterial communities and strains of the same species. Here, we consider the bacterial activities related to polluting oil hydrocarbondegrading communities, including those which are biosurfactant-producers,

Here, we showed that the isolation and screening strategy affected a lot, the selection of the hydrocarbon-degrading bacteria, by combining the bacterial tolerance to hydrocarbon toxicity to the hydrocarbons degradative activities. We demonstrated that se veral Qatari isolates are able to shift their activity from a range of hydrocarbons to another by the effect of the nitrogen source, $\mathrm{C} / \mathrm{N}$ ratio and organic nitrogen source. By application of Factorial Investigation of Strains' Potentiality to Degrade Hydrocarbons, which is original in the attempt to integrate the study of the most essential nutritional elements as well as their interactions in one experimental frame, we demonstrated diversity of nutritional requirements among the same bacterial group of Pseudomonas aeruginosa strain, isolated in Qatar. Strains' response to altered growth conditions varied substantially; although they were from the same taxonomical group.
\end{abstract}

Keywords: Bioremediation, hydrocarbons, Diesel, petroleum, polluted soils; biodegradation

\section{Introduction}

Remediation of contaminated soil and groundwater is vital to minimize the effects of accidental hydrocarbon releases and to protect these limited resources in many countries [1]. The oil polluting compounds are light hydrocarbons (oil, gasoline, diesel), heavy hydrocarbons (lubricants, heavy oil, crude oil), halogenated solvents, and other more complex molecules (aromatic hydrocarbons polycyclic, PAHs, etc.) [2]. Organic compounds are involved in nearly $75 \%$ of pollution of such polluted sites.

Microbial remediation is typically the preferred method for remediating subsurface hydrocarbon contamination, though it is often limited by low hydrocarbon aqueous solubility and strong sorption to soil [3]. On the other hand, it is obvious that exposure of hydrocarbons to the environment at polluted sites subjects them to various chemical, physical and biological degradation mechanisms such as oxidation, biodegradation and photo degradation [4]. Such factors make it difficult to predict and estimate the type of petroleum products in the polluted soil [3]. In addition, the physical and chemical characteristics of soils as well as weather conditions, affect a lot the chemical stability of the pollutants but also their availability to biodegradation. The hydrocarbons' composition, structure and occurrence depend on the pollution 
history, soil properties and weather conditions, affecting the occurrence, stability and biological activities of hydrocarbondegrading bacteria [5, 6]. In fact, this represents the main origin of failure of most of the bioremediation applications for cleaning polluted areas with hydrocarbons. It has been shown that the capacity of the microorganisms to degrade pollutants is not a result of just adding any type of species to polluted ecological sites, but the capacity of individual strains to produce appropriate biosurfactants and form a strong biodegrading association, and their ability to survive in the soil under natural conditions and with limited available nutrients and water [7, 8]. However, the extreme weather in certain regions leads over prolonged periods of time to the selection of adapted microorganisms to harsh conditions, but also to acquire new potentialities to remediate special composition of organics from soil or water $[6,9]$. We consider that bioprocesses of natural remediation in Qatar, an Arabian Gulf Country, is a suitable model to study hydrocarbons-degrading bacteria and how they deal with high variable composition and structure of hydrocarbons, especially under the extreme environmental conditions, and dry soils in Qatar [10].

In this study, we intend to isolate, screen and select bacterial strains able to degrade petroleum hydrocarbons specifically in recently or continuously polluted soils as well as area polluted over a very long period of time, all at the Qatari conditions. Ability of these bacteria to interact with a variable composition of pollutants is investigated through their growth, tolerance to toxicity and range of removed hydrocarbons.

\section{Material and Methods}

\subsection{Soil Samples}

Several amples were collected from various oil-contaminated sources, including the polluted seashore, near gas stations and in automotive workshops, using a sterile spatula at a tillage depth of 1-2 cm, randomly from different points. The soil samples were collected into sterilized glass bottles, properly sealed, labeled and warped with foil to prevent any further light reactions. All collected samples were temporally stored in an icebox at $4^{\circ} \mathrm{C}$ and then transferred to the laboratory for further analysis. Temperature of collected soils ranged from $35-36^{\circ} \mathrm{C}$.

\subsection{Culture Media}

For erichment Cultures and purification of isolates, Luria Broth (LB) medium) was used. Biodegradation experiments were performed in MSM liquid medium containing per liter ( $\mathrm{pH}$ 7.2): Nitrogen source either $\left(\mathrm{NH}_{4} \mathrm{NO}_{3}\right.$, $\mathrm{NH}_{4} \mathrm{Cl}$, or $\mathrm{NaNO}_{3}$ ) $4.0 \mathrm{~g} ; \mathrm{Na}_{2} \mathrm{HPO}_{4}, 2.0 \mathrm{~g} ; \mathrm{KH}_{2} \mathrm{PO}_{4}, 0.53 \mathrm{~g} ; \mathrm{K}_{2} \mathrm{SO}_{4}, 0.17 \mathrm{~g}, \mathrm{MgSO}_{4}, 7 \mathrm{H}_{2} \mathrm{O}, 0.10 \mathrm{~g}$, and $1 \mathrm{ml}$ trace element solution (per $100 \mathrm{ml}$ ) : EDTA, $0.1 \mathrm{~g} ; \mathrm{ZnSO}_{4}, 0.042 ; \mathrm{MnSO}_{4}, 0.178 \mathrm{~g} ; \mathrm{H}_{3} \mathrm{BO}_{3}, 0.05 ; \mathrm{NiCl}, 0.1 \mathrm{~g}$.

All media were sterilized at $121^{\circ} \mathrm{C}$ for 20 minutes.

\subsection{Isolation of hydrocarbon degrading Bacteria}

Luria Broth (LB) as used of enrichment medium with $2.5 \mathrm{~g}$ from each sample suspended in $25 \mathrm{ml}$. The liquid cultures were incubated at $30^{\circ} \mathrm{C}$ in a rotating shaker set at $300 \mathrm{rpm}$ for 3 days. After the incubation period, $2 \mathrm{ml}$ from each liquid culture were transferred to $25 \mathrm{ml}$ MSM liquid medium supplemented with $1 \mathrm{ml}$ crude oil (or diesel) as the sole carbon source. This step of adaptation of the microorganisms to oil/diesel as the sole carbon source was repeated twice to enrich the media only with microorganisms able to grow by using oil and diesel components as the carbon source. The spray plate technique [11] was also used to spread 100 $\mu$ l of LB-cultures (liquid MSM-cultures) on MSM agar medium and then $100 \mu \mathrm{l}$ crude oil/Diesel was spread on the surface of the MSM agar.

\subsection{Screening of diesel degrading isolates based on biomass production}

The best candidates for the degradation of petroleum components, were first cultured into $10 \mathrm{ml} \mathrm{LB}$ broth for 48 hours at $30^{\circ} \mathrm{C}$. Then, adaptation was performed by pouring into the respective sterilized $20 \mathrm{ml}$ MSM-diesel $10 \%$ or MSMpetroleum $10 \%$ liquid media supplemented with $10 \%$ diesel, crude oil respectively, and incubated for up to 2 weeks at $30^{\circ} \mathrm{C}$. The growth was then evaluated by spreading $100 \mu \mathrm{l}$ of serial dilutions in MSM medium on LB plates. Colony Forming Units (CFU) was used after enumeration as cell counts.

\subsection{Statistical analysis}

Three replicates were used throughout the experiments, and the mean values with standard deviation were calculated using Microsoft Excel 2013. 


\subsection{Molecular Identification of isolates}

Extraction of DNA was done from cells after overnight growth in LB plates. The cells were suspended in $0.5 \mathrm{ml}$ of distilled water, boiled for $10 \mathrm{~min}$ in a water bath and then centrifuged for $10 \mathrm{~min}$ at 13,000 rpm. The supernatant (total DNA) was placed in a new tube for PCR amplification. The $16 \mathrm{~s}$ rDNA fragment (1500 bp) was amplified using universal primers; RibS73sp 5'-AGAGTTTGATCCTGGCTCAG-3', and RibS74sp 5'-AAGGAGGTGATCCAGCCGCA-3' [12]. The sequencing of bacterial 16S rDNA amplicons was performed after purification, using Applied Biosystems 3500 Series Genetic analyzer system. The obtained 16S rDNA sequence of each isolate was used to determine the most closely related sequence of available sequences in Gene Bank database using the Blast server at NCBI.

\subsection{Analysis of diesel degradation by Gas Chromatography (GC)}

Analysis of diesel degradation by done by Gas Chromatography (GC) analysis, performed after the incubation periods using Perkin Elemer- Clarus $680 \mathrm{GC}$, FID detector at $150^{\circ} \mathrm{C}$ injector temperature. The diesel layer was carefully extracted using micropipette, placed into sterilized Eppendorf tube, centrifuged for $1 \mathrm{~min}$ at 13,000 rpm to separate any remaining liquid medium, and then the pure diesel layer was transferred to new sterilized Eppendorf tube and used for GC analysis. The biodegradation of diesel was concluded by the reduction in the area under the hydrocarbon peaks in the chromatograms when compared to that of the abiotic control, suggesting the removal of diesel componentsThe Removal Efficiency (RE) based on the decrease in peak area of selected hydrocarbons from the chromatogram of fresh diesel, was evaluated by using the following expression: $\operatorname{RE}(\%)=100$ - (As x 100/Ac); Where: As is the total area of the peak in each sample; Ac is the total area of the peak in the control and RE (\%) is the efficiency of biodegradation.

\section{Results}

\subsection{Isolation of hydrocarbon degrading bacteria}

Following the strategy designed in our work to isolate hydrocarbon-degrading bacteria both with high growth and biological activity, 39 purified bacterial isolates were recorded amongst hundreds of isolated ones at the first step of the program.

\subsection{Screening of bacterial isolates based on biomass production in $10 \%$ diesel}

Evaluation of the activity of all isolates was done for their ability to grow in the mineral salt medium (MSM) with $10 \%$ diesel as the sole carbon source. This diesel concentration of almost $75 \mathrm{~g} / 1$ hydrocarbons may be considered high, leading to the selection of bacterial strains with the highest ability to grow at such a concentration. The criterion of selection was the cells' biomass (cell counts) after 1 week and 2 weeks of incubation. The cell counts and growth rates were correlated to the ability of the isolate to use the diesel hydrocarbons (sole carbon source) at the experimental conditions. Results (not shown) show interesting isolates based on the reported selection criteria. Out of the preselected 23 isolates, 15 isolates showed relatively high growth, while 8 others showed moderate to low cell counts after 1 or 2 weeks of incubation.

\subsection{Screening of the strains based on their ability to degrade diesel hydrocarbons}

Biodegradation of diesel hydrocarbons was monitored by gas-chromatographic (GC) analysis, with FID detector. The diesel fraction separated from the cultural media (MSM medium) is fractionated by GC. Diesel from the control (culture not inoculated with cells) was used to select representative peaks covering a wide range from the low molecular weight (MW) hydrocarbons to high MW hydrocarbons. The degradation of the corresponding hydrocarbons was calculated as a reduction in the corresponding area from the chromatograms obtained similarly to that of control-diesel. It was expressed as a percentage of area reduction corresponding to the degraded hydrocarbon. This is in relation with the amount of the remaining fractions in the appropriate abiotic control samples as described by Michaud et al. [13]. The peaks were characterized by their retention time in the chromatogram. The Removal Efficiency (RE) of several isolates on 10\% diesel is shown in Fig.1. 

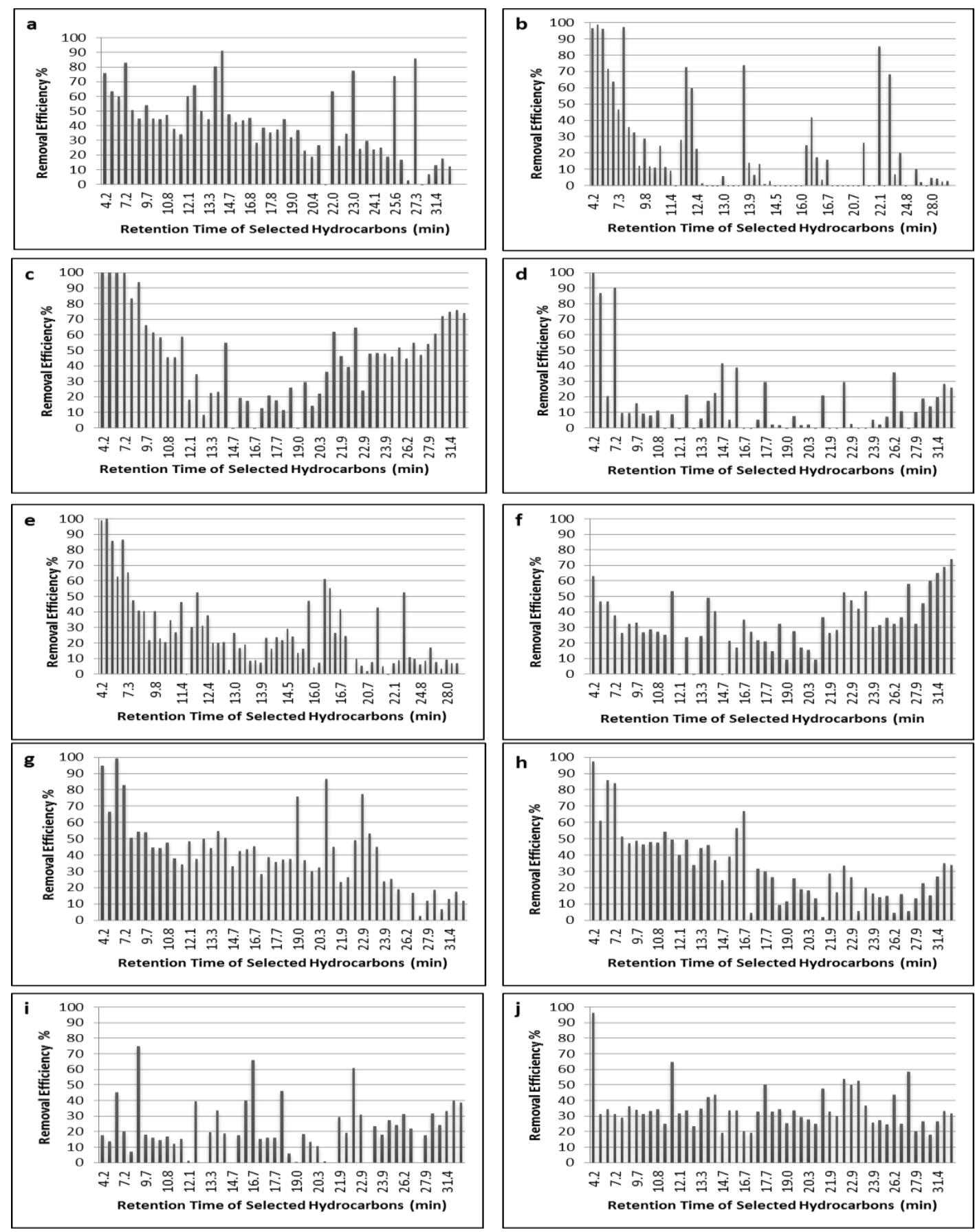

Fig. 1: Removal Efficiency (RE) of selected hydrocarbons on 10\% Diesel (indicated) by their retention time in their corresponding GC chromatograms of isolates: a) QDD1, b) QDD2, c) QDD3, d) QDD4, e) QDD5, f) QDD6, g) QDD7, h) QDD8, i) QDD9, and j) QDD10.

\subsection{Involvement of nitrogen source and $\mathrm{C} / \mathrm{N}$ ratio in the degradation of diesel hydrocarbons by selected strains}

The effect of the composition of the nitrogen source as well as the $\mathrm{C} / \mathrm{N}$ ratio on the biological activity of the selected strains was investigated. Three different nitrogen sources which are ammonium nitrate $\left(\mathrm{NH}_{4} \mathrm{NO}_{3}\right)$, ammonium chloride $\left(\mathrm{NH}_{4} \mathrm{Cl}\right)$, and Sodium Nitrate $\left(\mathrm{NaNO}_{3}\right)$, were used at different $\mathrm{C} / \mathrm{N}$ ratios $(60 / 1,80 / 1$ and 120/1 respectively) using $10 \%$ diesel corresponding to $75 \mathrm{~g} / \mathrm{l}$ total hydrocarbons. This may be considered actually, as a comparison between different conditions of growth. The results (not shown) 3 were obtained with three representative strains QDD8, QDD9 and QDD10. 
It was clear that QDD8 and QDD9 exhibit the highest growth rates when using Ammonium Nitrate as nitrogen source, while QDD10 has the highest growth with Ammonium Chloride. All strains have the lowest growth rates with Sodium Nitrate. It is clear that for each strain, there is a corresponding optimal $\mathrm{C} / \mathrm{N}$ or a range within which the growth is optimal. This growth dependence on $\mathrm{C} / \mathrm{N}$ ratio may vary from one nitrogen source to another at $10 \%$ diesel. The hydrocarbon degradation in diesel by each strain at all the conditions was evaluated by the GC analysis and calculation of the removal efficiency of representative hydrocarbons (Fig.2 to Fig.4).
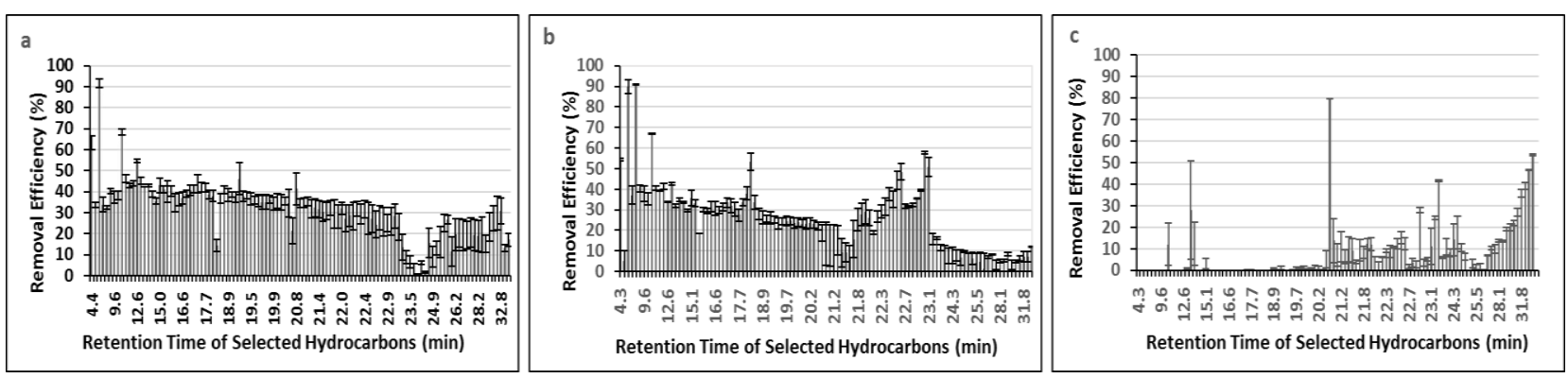

Fig. 2: Hydrocarbon Removal Efficiency QDD8 with nitrogen sources, a) $\mathrm{NH}_{4} \mathrm{NO}_{3}$, b) $\mathrm{NH}_{4} \mathrm{Cl}$, and c) $\mathrm{NaNO}_{3}$.
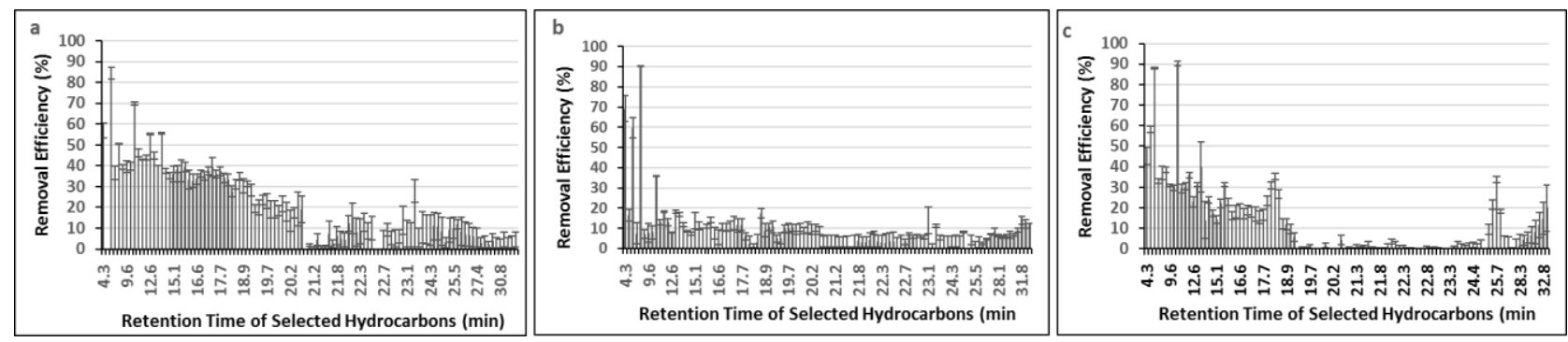

Fig. 3: Hydrocarbon Removal Efficiency QDD9 with nitrogen sources, a) $\mathrm{NH}_{4} \mathrm{NO}_{3}$, b) $\mathrm{NH}_{4} \mathrm{Cl}$, and c) $\mathrm{NaNO}_{3}$.
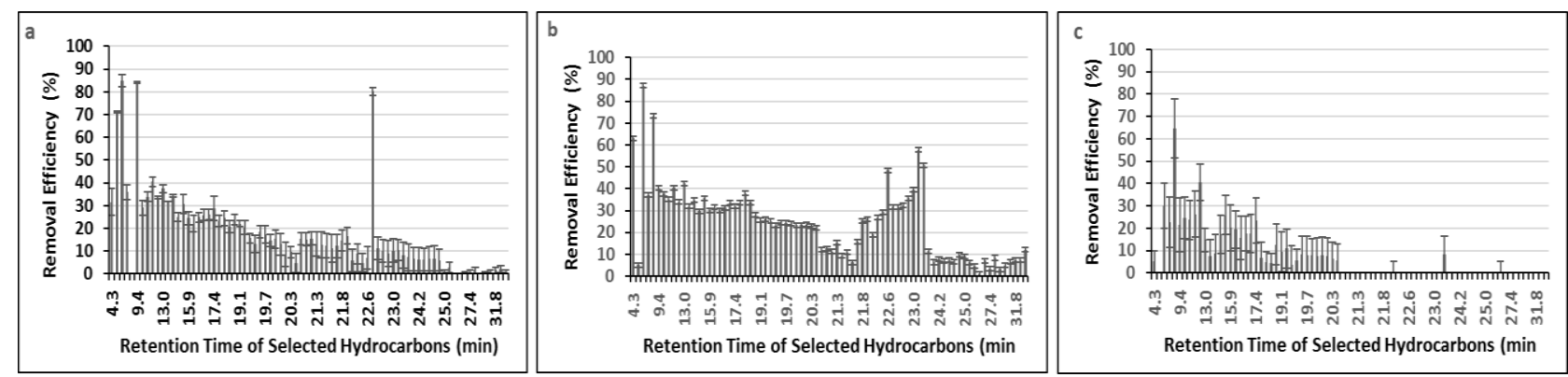

Fig. 4: Hydrocarbon Removal Efficiency QDD10 with different nitrogen sources, a) $\mathrm{NH}_{4} \mathrm{NO}_{3}$, b) $\mathrm{NH}_{4} \mathrm{Cl}$, and c) $\mathrm{NaNO}_{3}$.

Results of Fig.5 and Fig. 6, show high variability in the biological activity of the three strains at different conditions. Indeed, with ammonium, QDD8 was more active on high MW hydrocarbons at high a $\mathrm{C} / \mathrm{N}$ ratio of $50 / 1$. At higher $\mathrm{C} / \mathrm{N}$ ratio of 60, the overall activity was much higher, but less on high MW hydrocarbons.

With the strain QDD8, by using ammonium nitrate, the activity towards all the hydrocarbons was higher at $\mathrm{C} / \mathrm{N}$ of 60 . However, at C/N of 70/1, only high MW hydrocarbons were degraded. The strain QDD10, is not able to efficiently degrade medium MW hydrocarbons, but it is effective towards high MW ones at all conditions. The highest activity was obtained using ammonium nitrate at a $\mathrm{C} / \mathrm{N}$ ratio of $60 / 1$.

\subsection{Identification of the selected strains}

The most interesting isolates, showing high growth and removal efficiency of diesel hydrocarbons were identified based on sequencing of bacterial 16S rDNA amplicons, after purification. The obtained 16S rDNA sequence of each isolate was used to determine the most closely related sequence of available sequences in Gene Bank database using the 
Blast server at NCBI. Table 1 lists the identified isolates. 3 of our isolates are Pseudomonas aeruginosa, which are the most effective strains. There are also several strains of Arthrobacter, Citrobacter, Bacillus and Klebsiella. Unexpectedly, one of our isolates belongs to Klebsiella species.
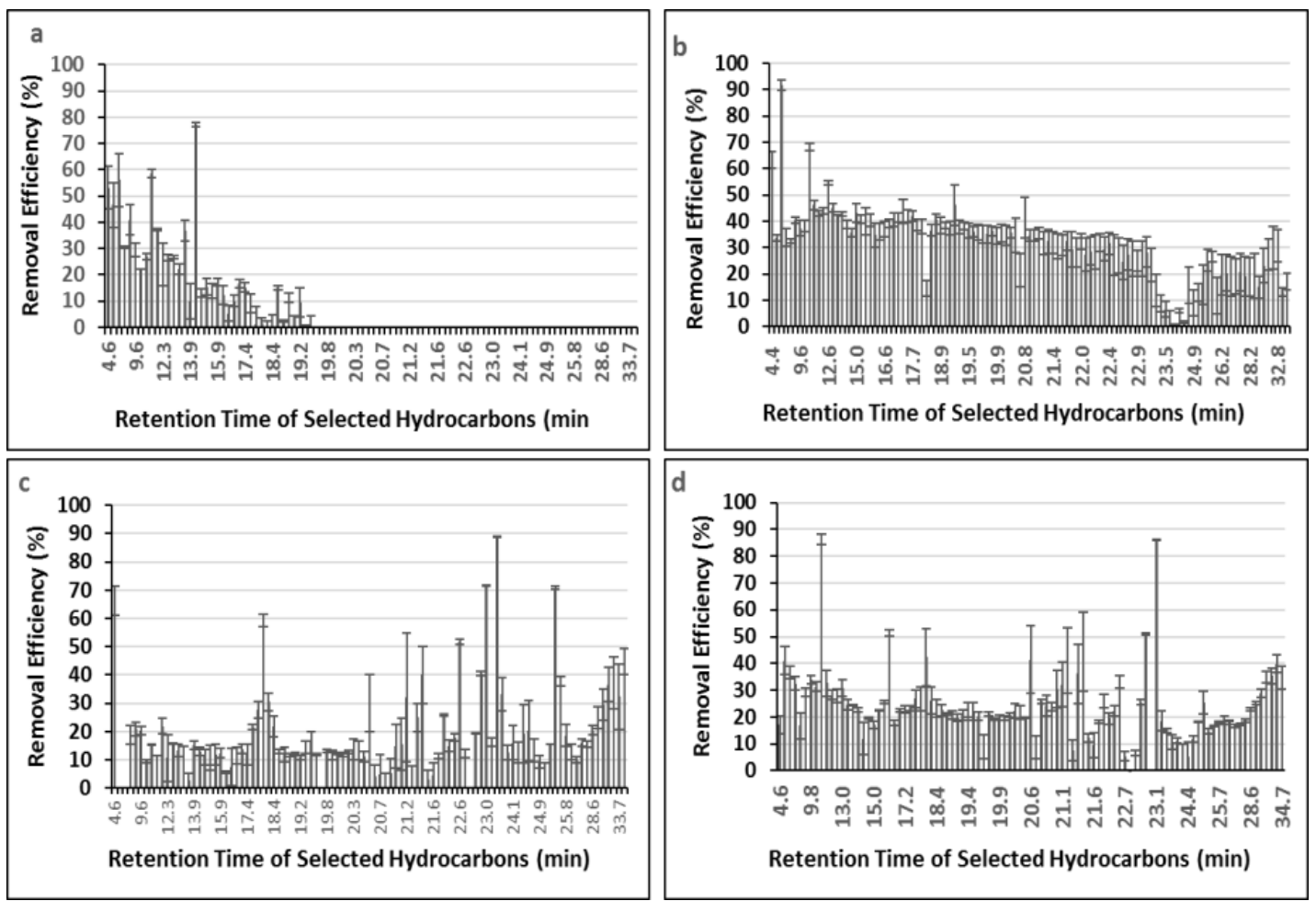

Fig. 5: Hydrocarbon Removal Efficiency of QDD8 with $\mathrm{NH}_{4} \mathrm{NO}_{3}$ at different C/N ratios: a) 70/1, b) 60/1, c) 50/1, and d) 40/1.
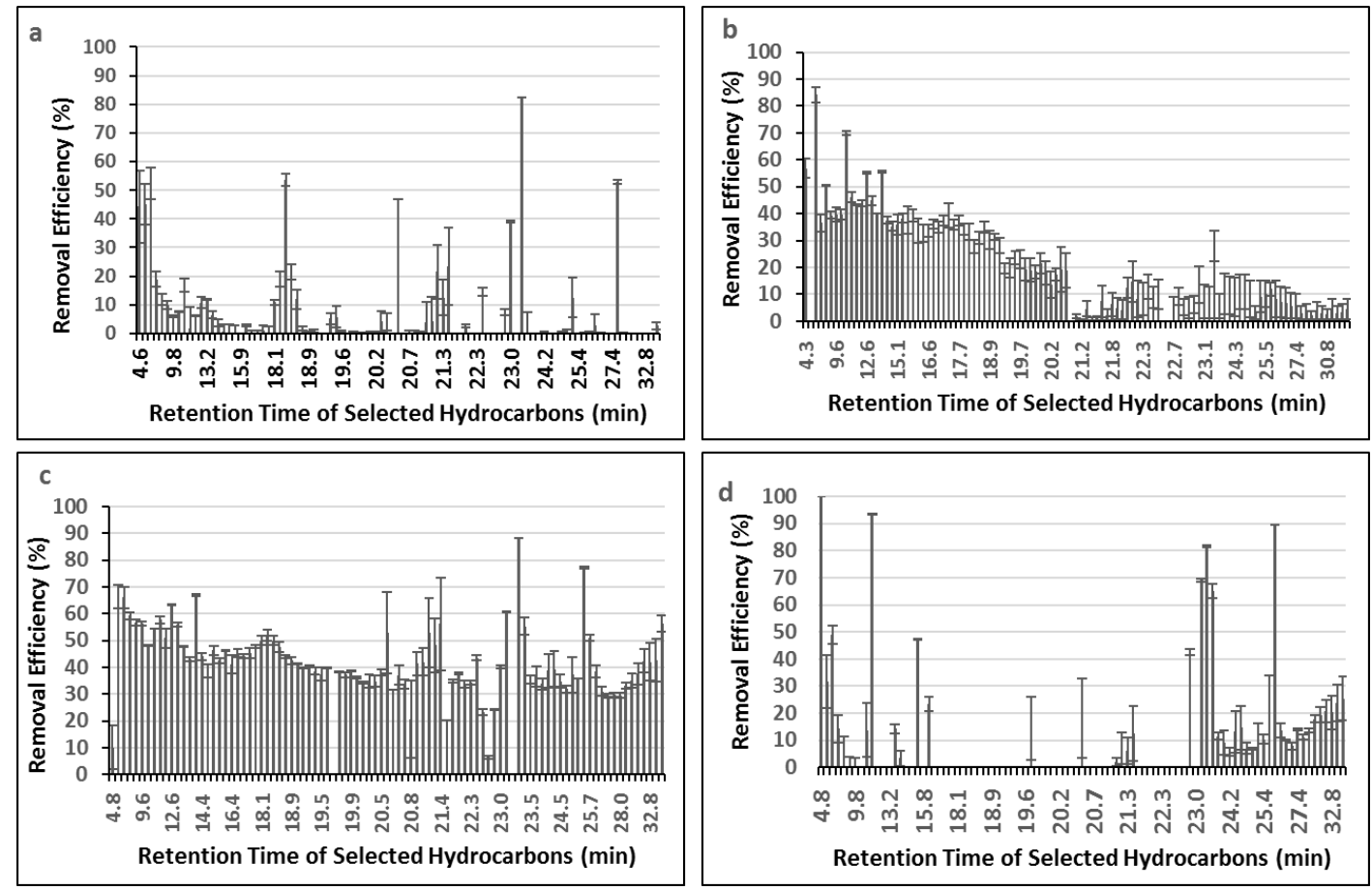

Fig. 6: Hydrocarbon Removal Efficiency of QDD9 with $\mathrm{NH}_{4} \mathrm{NO}_{3}$ at different $\mathrm{C} / \mathrm{N}$ ratios: a) 70/1, b) 60/1, c) 50/1, and d) 40/1. 
Table 1: List of identified diesel degrading strains.

\begin{tabular}{|c|l|c|}
\hline Isolate & Identity & Accession No. \\
\hline QDD1 & Pseudomonas aeruginosa & JX962696.1 \\
\hline QDD2 & Klebsiella pneumoniae & LC093517.1 \\
\hline QDD3 & Arthrobacter sp. & GU451067.1 \\
\hline QDD4 & Citrobacter sp. & KR063563.1 \\
\hline QDD5 & Citrobacter amalonaticus & KC689297.1 \\
\hline QDD6 & Enterobacter helveticus & JN255127.1 \\
\hline QDD7 & Cronobacter muytjensii & JN255123.1 \\
\hline QDD8 & Pseudomonas aeruginosa & JF919950.1 \\
\hline QDD9 & Pseudomonas aeruginosa & KC689297.1 \\
\hline QDD10 & Citrobacter amalonaticus & LN890172.1 \\
\hline QDD11 & Bacillus cereus & \\
\hline
\end{tabular}

\section{Discussion}

It is always recommended to follow an isolation and screening program to select microorganisms with expected biological activity, suitable to the objective of the application [14]. Here, the objective of the isolation program is to build a collection of bacterial strains exhibiting biological activity for the degradation of hydrocarbons from oil-polluted area. Most of the lost isolates were in the phase of purification, as a result of losing hydrocarbon degrading activity, known to be exhibited by plasmidic genes that lack several growth conditions [15]. All the retained isolates are supposed to be more genetically stable. It was interesting to diversify media and conditions in the isolation program. Two different media, named MSM and MM, the most used media for isolation of hydrocarbon-degrading bacteria were used [11]. Moreover, to increase the chance of isolating interesting bacterial strains, diesel and crude oil were used as the sole hydrocarbon sources, at $10 \%(\mathrm{v} / \mathrm{v})$ corresponding to almost $75 \mathrm{~g} / \mathrm{l}$ hydrocarbons (Um-Saeed Refinery, Qatar personal communication). This may be considered as a high hydrocarbon concentration, with a potential toxicity towards most of the microorganisms. The isolates, purified through this program should tolerate high hydrocarbon concentrations and their potential toxicity. Indeed, the high selection pressure should lead to the isolation of suitable isolates for the bioremediation of oil hydrocarbons [16]. On the other hand, the isolation was performed from a recently polluted area and from an area polluted over a very long period of time. This may provide both, the adaptation of bacteria to the pollution potential of hydrocarbons (natural selection of microorganisms) and to different compositions of the hydrocarbons [17]. Indeed, hydrocarbons are characterized by chemical instability with modifications in their structures due to oxidation and light occurring in nature [18]. Diversification of samples as well as media and hydrocarbons led to a potential large variety of isolates with biological activities, which may be different [19]. To explain these results, we can postulate two hypotheses:

Hypothesis 1: The nitrogen sources are responsible for providing nitrogen for the synthesis of cells' components. This may be performed differently from one nitrogen source to another. Since, in the used MSM media, there are no supplemental amino acids, the addition of amino acids to the media may increase the rate of growth, depending on the nitrogen source.

Hypothesis 2: In the three media, there is the same carbon source concentration (10\% diesel corresponding to almost $75 \mathrm{~g} / \mathrm{l}$ hydrocarbon concentration) but different nitrogen concentrations supplied by the different nitrogen sources. The $\mathrm{C} / \mathrm{N}$ ratios are of 60/1 in MSM1, 80/1 in MSM2 and 120/1 in MSM3. The study of the effect of C/N ratio on the growth was necessary. The effect of the composition of the nitrogen source as well as the $\mathrm{C} / \mathrm{N}$ ratio on the biological activity of the selected strains showed that the biological activity of each strain might shift from a range of hydrocarbons MW to another. This finding is of importance, since it is possible to implement the isolated bacterium for the degradation of the available hydrocarbons in the polluted site. 3 of the isolates are Pseudomonas aeruginosa, which are the most effective strains [2022]. This result is expected due to the fact that this species is the most involved in bioremediation, especially of hydrocarbons. There are also several strains of Arthrobacter, Citrobacter, Bacillus and Klebsiella. These species are also reported in literature for their biological activities for bioremediation of hydrocarbon [20-22]. Unexpectedly, one of our isolates belongs to Klebsiella species. Up to know, it is not reported how Klebsiella which is normally pathogenic, exhibits such biological activity. Several strains of Bacillus cereus and Bacillus thuringiensis are also shown with some activity of 
degradation of hydrocarbons. In literature, it is not reported that Enterobacter helveticus or Cronobacter muytjensii, are involved in degradation of hydrocarbon [21, 22] It was clearly observed that the biological activity for each strain was affected and shifted towards higher molecular weight hydrocarbons by changing the nitrogen source and altering $\mathrm{C} / \mathrm{N}$ ratios. This is a result of high adaptation of these bacteria to the local environmental conditions, in term of chemicals composition and harsh conditions.

\section{Acknowledgements}

This study was supported by Internal Grant from the College of Arts and Sciences, Qatar University.

\section{References}

[1] N. Das, and P. Chandran, "Microbial Degradation of Petroleum Hydrocarbon Contaminants: An Overview," Biotechnology Research International, pp. 1-13, 2011.

[2] R. Brewer, J. Nagashima, M. Kelley, M. Heskett, and M. Rigby, "Risk-Based Evaluation of Total Petroleum Hydrocarbons in Vapor Intrusion Studies," International Journal of Environmental Research and Public Health, vol. 10, no. 6, pp. 2441-2467, 2013.

[3] C. S. Ezeonu, R. Tagbo, E. N. Anike, O. A. Oje, and I. N. E. Onwurah, "Biotechnological Tools for Environmental Sustainability: Prospects and Challenges for Environments in Nigeria-A Standard Review," Biotechnology Research International, pp. 1-26, 2012.

[4] R. Atlas, and J. Bragg, "Bioremediation of marine oil spills: when and when not - the Exxon Valdez experience," Microbial Biotechnology, vol. 2, no. 2, pp. 213-221, 2009.

[5] R. Iturbe, and J. López, "Bioremediation for a Soil Contaminated with Hydrocarbons," Journal of Petroleum \& Environmental Biotechnology, vol. 6, no. 2, pp. 1-6, 2015.

[6] H. S. Kim, and P. R. Jaffé, "Spatial distribution and physiological state of bacteria in a sand column experiment during the biodegradation of toluene," Water Research, vol. 41, no. 10, pp. 2089-100, 2007.

[7] A. Jonsson, and H. Haller, "Sustainability Aspects of In-Situ Bioremediation of Polluted Soil in Developing Countries and Remote Regions," In Environmental Risk Assessment of Soil Contamination, M. C. Hernandez-Soriano, INTECH, 2014, pp. 57-86.

[8] A.K. Karamalidisa, A.C. Evangeloua, E. Karabikab, A.I. Koukkoub, C. Drainasb, and E.A. Voudriasa, "Laboratory scale bioremediation of petroleum-contaminated soil by indigenous microorganisms and added Pseudomonas aeruginosa strain Spet," Bioresource Technology, vol. 101, no. 16, pp. 6545-6552, 2010.

[9] M. N. Battikhi, "Bioremediation of Petroleum Sludge," Journal of Microbiology \& Experimentation, vol. 1, no. 2, pp. $1-3,2014$.

[10] C. Jhonson, Biology of Soil Science, First Edition. Delhi: Oxford Book Company, 2009.

[11] S. Survery, S. Ahmad, S. Abu-Subhan, M. Ajaz, and S. A. Rasool, "Hydrocarbon Degrading Bacteria From Pakistani Soil: Isolation, Identification, Screening and Genetical Studies," Pakistani Journal of biological Science, vol. 7, no. 9, pp. 1518-1522, 2005.

[12] M. Xiao, and J.H. Zhang, "Rhodobacter azotoformans strain Y6 16S ribosomal RNA gene, partial sequence," State Key Laboratory of Microbial Technology Province, 250100, 2011.

[13] L. Michaud, A. L. Giudice, M. Saitta, M. De Domenico, and V. Bruni, "The biodegradation efficiency on diesel oil by two psychrotrophic Antarctic marine bacteria during a two-month-long experiment," Marine Pollution Bulletin, vol. 49, pp. 405-409, 2004.

[14] A. Mittal, and P. Singh, "Isolation of hydrocarbon degrading bacteria from soils contaminated with crude oil spills," Indian Journal of Experimental Biology, vol. 47, no. 9, pp. 760-5, 2009.

[15] Oluwafemi, S. Obayori, and B. S. Lateef, "Degradation of polycyclic aromatic hydrocrbon: Role fo Plasmids," Scientific Reasearch and Essays, vol. 5, no. 25, pp. 4093-4106, 2010.

[16] M. Kastner, M. Breuer-Jammlia, and B. Mahroe, "Enumeration and characterization of the soil microflora from hydrocarbon contaminated soil sites able to mineralize Polycyclic Aromatic Hydrocarbon (PAH)," Applied Microbioloy and Biotechnoloy, vol. 41, no. 2, pp. 267-273, 1994.

[17] S.K. Lotfabad, and M.R. Gray, "Kinetics of biodegradation of mixtures of polycyclic aromatic hydrocarbons," Applied Microbiology and Biotechnology, vol. 60, pp. 361-365, 2002. 
[18] A. Masih, and A. Taneja, "Polycyclic aromatic hydrocarbons (PAHs) concentrations and related carcinogenic potencies in soil at a semi-arid region of India," Chemosphere, vol. 65, no. 3, pp. 449-456, 2006.

[19] A. R. Johnsen, S. Schmidt, K. T. Hybholt, S. Henriksen, S. C. Jacobsen, and O Anderson, "Strong Impact on the Polycyclic Aromatic Hydrocarbon (PAH)-Degrading Community of a PAH-Polluted Soil but Marginal Effect on PAH Degradation when Priming with Bioremediated Soil Dominated by Mycobacteria," Applied and Environmental Microbiology, vol. 73, pp. 1474-1480, 2007.

[20] K. E. Nelson, C. Weinel, I. T. Paulsen, R. J. Dondson, H. Hilbert, V. A. Martins dos Santos, D. E. Fouts, and S. R. Gill, "Complete genome sequence and comparative analysis of the metabolically versatile Pseudomonas putida KT2440," Environmental Microbiology, vol. 4, no. 12, pp. 799-808, 2002.

[21] P. Golyshin, M. D. Santos, O. Kaiser, M. Ferrer, Y. Sabirova, H. Lünsdorf, T. Chernikova, et al., "Genome sequence completed of Alcanivorax borkumensis, a hydrocarbon-degrading bacterium that plays a global role in oil removal from marine systems," Journal of Biotechnology, vol. 106, no. 3, pp. 215-220, 2003.

[22] J. Jung, J. H. Baek, and W. Park, "Complete genome sequence of the diesel-degrading Acinetobacter sp. strain DR1," Journal of Bacteriology, vol. 192, no. 18, pp. 4794-5, 2010. 